\title{
miR-135b, upregulated in breast cancer, promotes cell growth and disrupts the cell cycle by regulating LATS2
}

\author{
KAIYAO HUA ${ }^{1,2}$, JIALI JIN ${ }^{3}$, JUNYONG ZHAO ${ }^{1}$, JIALU SONG ${ }^{1}$, HONGMING SONG ${ }^{1}$, DENGFENG LI ${ }^{1}$, \\ NIRAJ MASKEY ${ }^{1}$, BINGKUN ZHAO $^{1,2}$, CHENYANG WU $^{1}$, HUI XU ${ }^{1}$ and LIN FANG ${ }^{1}$ \\ ${ }^{1}$ Department of Breast and Thyroid Surgery, Shanghai Tenth People's Hospital, Tongji University \\ School of Medicine, Shanghai 200072; ${ }^{2}$ Nanjing Medical University, Nanjing 210029; \\ ${ }^{3}$ Tongji University School of Medicine, Shanghai 200072, P.R. China
}

Received December 4, 2015; Accepted January 27, 2016

DOI: 10.3892/ijo.2016.3405

\begin{abstract}
Dysregulation of microRNAs (miRNAs) plays a critical role in cancer progression. They can act as either oncogenes or tumor suppressor genes in human cancer. The purpose of this study was to investigate the crucial role of miR-135b in breast cancer and to validate whether miR-135b could regulate proliferation of breast cancer cells by effecting specific targets in the Hippo pathway. Quantitative reverse transcription polymerase chain reaction (qRT-PCR) was carried out to quantify the expression levels of miR-135b in both breast cancer tissues and cell lines. To characterize the function of miR-135b, MTT assays, colony formation assays, cell migration assays, cell invasion assays, and cell cycle assays were used. Luciferase reporter assays were performed to validate the regulation of a putative target of miR-135b, in corroboration with western blot assays. Finally, we verified the changes of cellular function after transfection of LATS2-siRNA. Our experiments indicate that expression of miR-135b was commonly upregulated in breast cancer specimens and breast cancer cells when compared with that in adjacent normal tissues and non-malignant breast epithelial cells. Enforced expression of miR-135b can regulate cellular proliferation, migration and invasion as well as disrupt the cell cycle of breast cancer cells. Luciferase assays revealed that miR-135b directly bound to the 3 '-untranslated region (3'-UTR) of LATS2 (large tumor suppressor kinase 2), a critical gene in the Hippo pathway. Western blot analysis verified that miR-135b regulated the expression of LATS2 at protein levels. Further study demonstrated that the downstream gene of LATS2 in the Hippo pathway, such as cyclin-dependent kinase 2 (CDK2) and Phospho-Yes-associated protein
\end{abstract}

Correspondence to: Professor Lin Fang or Dr Kaiyao Hua, Department of Breast and Thyroid Surgery, Shanghai Tenth People's Hospital, Tongji University School of Medicine, 301 Yanchang Road, Zhabei Area, Shanghai 200072, P.R. China

E-mail: fanglin_f@126.com

E-mail: huakaiyao111@163.com

Key words: miR-135b, breast cancer, large tumor suppressor kinase 2
(p-YAP), can also be regulated by miR-135b and LATS2 axis. Knockdown of endogenous LATS2 can mimic the result of miR-135b upregulation in breast cancer. Taken together, our findings reveal that the miR-135b and LATS2 axis may be a potential therapeutic target for breast cancer in the future.

\section{Introduction}

Breast cancer is one of the most common female maligant tumors and a leading cause of cancer mortality worldwide each year (1). Genetic mutations have been demonstrated to be causative of tumorigenesis in breast cancer. At this point, it is essential to develop more effective methods for early diagnosis and treatment.

MicroRNAs (miRNAs) are small, non-coding RNAs of approximately 19-25 nucleotides acting as critical regulators of gene expression $(2,3)$. Mature miRNA plays its role by binding to the 3'-untranslated regions (3'-UTRs) of certain mRNAs, suppressing target gene expression $(4,5)$. In recent decades, miRNAs are confirmed to be involved in many important physiological and pathological processes, such as cell proliferation, differentiation, virus infection and tumorigenesis, and are widely dyregulated in various cancers, suggesting that they may function as either tumor-suppressor genes or oncogenes $(6,7)$. Alteration of miRNA expression has emerged to be one of the key features in cancer-associated dysfunction of gene regulatory networks, which can improve cancer classification, diagnosis, and clinical prognostic information (8). miRNA has become a hot spot in breast cancer research whereby miRNAs are believed to have broad prospects in terms of diagnosis and treatment of this disease.

The Hippo pathway, firstly discovered in Drosophila melanogaster, is widely considered to be a signaling pathway that is important in controlling organ size and tumor progression by regulating cellular proliferation and promoting apoptosis (9). In recent years, accumulated evidence suggests that the Hippo signaling pathway plays crucial roles in breast cancer. LATS2 (large tumor suppressor kinase 2) is an AGC kinase of the NDR family of kinases. It is a tumor suppressor of the LATS family, and plays a significant role in centrosome duplication, maintenance of mitotic fidelity, and genomic stability (10). LATS2 inhibits cell growth 
at the G1/S transition by downregulating cyclin E/CDK2 kinase activity (11). As an upstream regulator in the Hippo pathway, LATS2 can regulate its downstream gene YAP (Yes-associated protein). Specifically, phosphorylated and activated LATS2 can phosphorylate transcription coactivators YAP, leading to the YAP cytoplasm retention by 14-3-3 protein or degradation $(12,13)$. To date, several other miRNAs have been proved to target LATS2 in different types of cancer. miR-181b regulates ovarian cancer cell growth and invasion by targeting LATS2 (14). miR-93 can promote tumor angiogenesis and metastasis by suppressing LATS2 in human breast cancer cells (15). miR-372 disrupts cell cycle in gastric cancer cells through direct regulation of LATS2 (16). Recent studies indicate that miR-135b is elevated in a variety of cancers such as lung cancer, colorectal cancer and hepatocellular cancer, and it is also confirmed to be implicated in cancer growth, survival, motility, and invasiveness (17-19). However, the specific expression features of miR-135b in breast cancer remains undefined, and the potential role and its mechanism of action are still unknown.

Our present study aimed to investigate the function of miR$135 \mathrm{~b}$ in breast cancer cells. Using qRT-PCR, both our breast cancer tissue samples and cancer cell lines had higher miR-135b expression levels, as predicted. Moreover, miR-135b serves as an oncogene in breast cancer and is a vital regulator of cellular proliferation, migration, invasion and cell cycle. LATS2 was found to have binding sites for miR-135b in the 3'UTR region. We demonstrated that LATS2 is a direct target of miR-135b. As the downstream gene of LATS2, CDK2 and p-YAP was regulated by miR-135b and LATS2 axis. These results suggest that miR-135b may act as a biomarker in breast cancer and that downregulation of miR-135b is a feasible therapeutic approach for breast cancer that merits further evaluation.

\section{Materials and methods}

Specimens and cell lines. In our study, 16 pairs of breast cancer and adjacent normal specimens were collected from the Department of Breast and Thyroid Surgery of Shanghai Tenth People's Hospital, Shanghai, China. The samples were immediately snap-frozen in liquid nitrogen. Both tumor and normal tissues were histologically confirmed by more than one experienced pathologist according to the World Health Organization (WHO) using H\&E (hematoxylin and eosin) staining, and none of these patients had received any chemotherapy or radiotherapy prior to surgery.

The human breast cancer cell lines MDA-MB-231, MCF-7, MDA-MB-436, HCC1937 and non-malignant breast epithelial cell line MCF-10A were purchased from Chinese Academy of Sciences in Shanghai. The breast cancer cells were maintained in Dulbecco's modified Eagle's medium (DMEM) (Gibco, Grand Island, NY, USA) supplemented with 10\% Fetal Bovine Serum (FBS) (Gibco), penicillin (100 U/ml) and streptomycin $(100 \mu \mathrm{g} / \mathrm{ml})$ (Enpromise, Hangzhou, China). MCF-10A cells were cultured in Mammary Epithelial Basal Medium (MEBM) (Cambrex). All the cells were incubated at $37^{\circ} \mathrm{C}$ in a humidified chamber supplemented with $5 \% \mathrm{CO}_{2}$.

Transfection assay. MiR-135b mimics, inhibitor, LATS2siRNA and their negative control (NC) were chemosynthesized by Shanghai Genepharma Co., Ltd. (Shanghai, China). Cells $\left(1 \times 10^{6}\right)$ were added into each well of a 6-well plate and cultured with DMEM medium without serum and antibiotics. When the confluency of breast cancer cells reached $30-50 \%$, miR-135b mimics, miR-135b inhibitor, LATS2-siRNA and NC were transfected at working concentrations using Lipofectamine 2000 (Invitrogen, Carlsbad, CA, USA) according to the manufacturer's instructions. After 4-5 h of incubation, DMEM medium was replaced by DMEM with $10 \%$ FBS, and all the cells were incubated at $37^{\circ} \mathrm{C}$ in a $\mathrm{CO}_{2}$ incubator for $24 \mathrm{~h}$ prior to further testing.

$R N A$ extraction and quantitative reverse-transcription $P C R$ ( $q R T-P C R)$. According to the manufacturer's protocol, total RNA was extracted from the cells or tissues using TRIzol (Invitrogen). For detection of miR-135b expression, primer design and qRT-PCR were carried out according to the manufacturer's instructions. The primers used were as followed: miR-135b forward, 5'-GCTTATGGCTTTTCATT CCT-3', reverse, 5'-GTGCAGGGTCCGAGGT-3'; U6 forward, 5'-CTCGCTTCGGCAGCACA-3', reverse, 5'-AAC GCTTCACGAATTTGCGT-3'. cDNA was generated by reverse transcription using the PrimeScript ${ }^{\mathrm{TM}}$ RT-PCR kit in accordance with the manufacturer's instructions (Takara, Tokyo, Japan). Real-time PCR was performed on a 7900HT Fast RT-PCR instrument (Applied Biosystems, Singapore). The amplification procedure was as follows: $5 \mathrm{~min}$ at $95^{\circ} \mathrm{C}$, followed by 40 cycles at $95^{\circ} \mathrm{C}$ for $30 \mathrm{sec}$ and $65^{\circ} \mathrm{C}$ for $45 \mathrm{sec}$. The relative expression was evaluated following the relative quantification equation, $2^{-\Delta \Delta C T}$. Each sample was tested in triplicate.

Quantitative detection of LATS2 was implemented using the same strategy. The primers used were as followed: LATS2 forward, 5'-CTGGAATTCGAAGTGTGAGCAAGGTG ATG-3', reverse, 5'-ACGACTAGTGACTTGAGTATGCC ACTCAC-3'; $\beta$-actin forward, 5'-CATGTACGTTGCTAT CCAGGC-3', reverse, 5'-CTCCTTAATGTCACGCACGAT-3'. The PCR parameters for relative quantification were as follows: $2 \mathrm{~min}$ at $95^{\circ} \mathrm{C}$, followed by 40 cycles of $45 \mathrm{sec}$ at $57^{\circ} \mathrm{C}$ and $45 \mathrm{sec}$ at $72^{\circ} \mathrm{C}$. The relative expression was evaluated following the relative quantification equation, $2^{-\Delta \Delta C T}$. Each sample was tested in triplicate.

Cell proliferation assay (MTT assay). Cell proliferation was detected using an MTT assay kit (Sigma, Santa Clara, CA, USA) in accordance with the manufacturer's instructions. In brief, the transfected cells $\left(2 \times 10^{3}\right.$ cells/well $)$ were seeded into 96-well culture plates (BD Biosciences, Franklin Lakes, NJ, USA) and incubated overnight at $37^{\circ} \mathrm{C}$ in $5 \% \mathrm{CO}_{2}$. Cell proliferation was assessed at 24, 48, 72 and $96 \mathrm{~h}$ following addition of $0.5 \mathrm{mg} / \mathrm{ml}$ MTT (Sigma) solution. After a 4-h incubation, the medium was replaced by $150 \mu 1$ dimethylsulfoxide (DMSO; Sigma). After 10 min of agitation (100 rpm), optical density at $490 \mathrm{~nm}$ was determined on a microplate spectrophotometer. Each sample was tested with six replicates. All experiments were performed in biological triplicate.

Colony formation assay. Three hundred cells of each group were plated in a 6 -well plate in complete medium $4 \mathrm{~h}$ after transfection. The plates were shaken to disperse the cells equally. After 7-10 days, or when the colonies were visible, the culture 
was terminated and the plates were washed twice in phosphate buffered saline (PBS) after removing the complete medium. Then the colonies were fixed in $95 \%$ ethanol for $10 \mathrm{~min}$, dried and stained with $0.1 \%$ crystal violet solution for $10 \mathrm{~min}$. Then, each plate was washed three times with water, and the number of colonies was counted only if the well contained $>50$ cells. The experiment was performed three times.

Wound-healing assay. In the in vitro wound healing assay, transfected cells were cultured in 6-well plates until the cell confluence reached $\sim 90 \%$. Then the plates were washed in PBS after making a scratch in each well using a sterile pipette tip. Wound-healing was observed under a light microscope and images were captured at the same view at $0,12,24$ and $48 \mathrm{~h}$ after scratching to observe the process of wound healing. The experiments were repeated twice and representative photographs are shown.

Transwell invasion assay. A Transwell invasion assay was performed by using Chemicon Cell Invasion Assay kit (Chemicon, Temecula, CA, USA). The miR-135b mimics or miR-135b inhibitor transfected cells $\left(5 \times 10^{4}\right.$ cells/Transwell $)$ were plated in the top chamber of Transwells with a Matrigel ( $2 \mathrm{mg} / \mathrm{ml}$ )-coated membrane containing 8-mm diameter pores in $200 \mu \mathrm{l}$ serum-free DMEM. The lower chambers were filled with $500 \mu \mathrm{l}$ of DMEM containing $10 \%$ FBS. After $48 \mathrm{~h}$ of incubation, the membrane was stained with $0.1 \%$ crystal violet and observed under a microscope after removing the Matrigel and cells in the upper chambers. Five fields were randomly selected from each membrane, and the number of cells penetrating the membrane was counted at a magnification of $\mathrm{x} 200$. The invasion ability was described as the number of invading cells. Each experiment was carried out in triplicate.

Cell cycle assay. At $24 \mathrm{~h}$ after transfection, cells were trypsinized and centrifuged at $1000 \mathrm{rpm}$ for $5 \mathrm{~min}$, followed by two washes in cold PBS. Then cells were fixed in $70 \%$ ice-cold ethanol at $4^{\circ} \mathrm{C}$ for $24 \mathrm{~h}$. A total of $250 \mu \mathrm{l} 0.05 \mathrm{~g} / \mathrm{l}$ propidium iodide (PI) staining solution was added into each sample and incubated for $30 \mathrm{~min}$ at room temperature, and cell cycle distribution was analyzed using flow cytometry (FACSCanto ${ }^{\mathrm{TM}} \mathrm{II}$, BD Biosciences, San Jose, CA, USA).

Dual-luciferase reporter assay. HEK293T cells were seeded in 12-well plates (BD Biosciences) and cultured until the cells reached $80-90 \%$ confluence. The 3'-UTR segments of the LATS2 mRNA sequence containing the predicted miR-135b binding sites were amplified by PCR using the PrimerStar kit (Takara). The corresponding mutant constructs were created by mutating the seed regions of the miR-135b-binding sites (5'-AAGCCAUA-3' to 5'-AACAGTUA-3'). The mutant constructs were generated by mutation. The forward primer used in the reaction was 5'-CTGGAATTCGAAGTGTGAGC AAGGTGATG-3'; and the reverse primer was 5'-ACGA CTAGTGACTTGAGTATGCCACTCAC-3'. Fragments were subcloned into the XhoI site in the 3'-UTR of Renilla luciferase of the psiCHECK-2 reporter vector. Cells were transiently cotransfected with $0.2 \mu \mathrm{g}$ psiCHECK-2/LATS2 3'-UTR or psiCHECK-2/LATS2 3'-UTR mutant reporter plasmids and together with $100 \mathrm{nmol} / \mathrm{l} \mathrm{miR}-135 \mathrm{~b}$ or miR-NC using
Lipofectamine $^{\mathrm{TM}} 2000$ (Invitrogen), according to the manufacturer's instructions. After $48 \mathrm{~h}$, firefly and Renilla luciferase activities were measured by using a Dual Luciferase Assay (Promega, Madison, WI, USA). Firefly luciferase activity was normalized to Renilla, and the ratio of firefly/renilla was recorded.

Western blotting. Cells were washed in ice-cold PBS and resuspended in RIPA lysis buffer (100 $\mu \mathrm{l} /$ well, Beyotime). Then the cells were collected and centrifuged for $30 \mathrm{~min}$ at $4^{\circ} \mathrm{C}$ (Eppendorf 5804R, Eppendorf Biotech, Hamburg, Germany). Supernatants were collected and the protein concentrations were quantified using a BCA protein assay kit (Beyotime). Protein samples were denatured with 5X SDS loading buffer (Beyotime) at $100^{\circ} \mathrm{C}$ for $10 \mathrm{~min}$. Total protein was separated by $8 \%$ sodium dodecyl sulfate polyacrylamide gel electrophoresis (SDS-PAGE, Beyotime) and transferred to a $0.45-\mu \mathrm{m}$ nitrocellulose membrane (Beyotime). The membrane was incubated at $4^{\circ} \mathrm{C}$ with primary antibodies against LATS2 (1:1,000; Bioworld Technology; Nanjing, China), CDK2 (1:1,000; Bioworld Technology), p-YAP (1:1,000; Cell Signaling Technology, USA) and $\beta$-actin (1:1,000; Bioworld Technology). After washing with PBST (Shanghai Engineering Co.), the membranes were incubated with secondary antibodies for $60 \mathrm{~min}$. Immunereactive protein bands were detected with an Odyssey Scanning system.

Statistical analysis. Data are presented as the means \pm standard deviation (SD) from at least three independent experiments. The Student's t-test was used to evaluate the differences between each group in SPSS 20.0 software. Differences were considered significant for P-values $<0.05$.

\section{Results}

miR-135b is upregulated in both human breast cancer specimens and breast cancer cell lines. Abnormal expression of miR-135b has been demonstrated in a variety of cancers (20-27). To explore the role of miR-135b in human breast cancer, we analyzed 16 pairs of breast cancer tissues and adjacent normal specimens in this study. Total RNAs were isolated from excised tumor tissues and benign tissues of patients with breast cancer. Analysis of miR-135b by realtime PCR indicated that miR-135b levels were obviously upregulated in breast cancer tissues compared with benign tissues $(\mathrm{P}<0.05$, Fig. 1A), and a significant upregulation was found in 12 of 16 patients $(\mathrm{P}<0.05, \mathrm{P}<0.01$, Fig. $1 \mathrm{~B})$. Moreover, expression of miR-135b was also demontrated to be upregulated in all four collected breast cancer cell lines compared to MCF-10A, a non-malignant breast epithelial cell line $(\mathrm{P}<0.05$, $\mathrm{P}<0.01, \mathrm{P}<0.001$, Fig. 1C). These results imply a potential role of miR-135b in breast cancer. In this experiment, we also explored the relationship between the number of metastatic axillary lymph nodes and the relative miR-135b expression, noteworthy, a positive correlation was found between the two variables $(r=0.737, \mathrm{P}<0.01$, Fig. 1D).

miR-135b promotes the proliferation of breast cancer cells in vitro. To explore the potential role of miR-135b in human breast cancer, we first detected the effect of miR-135b on 

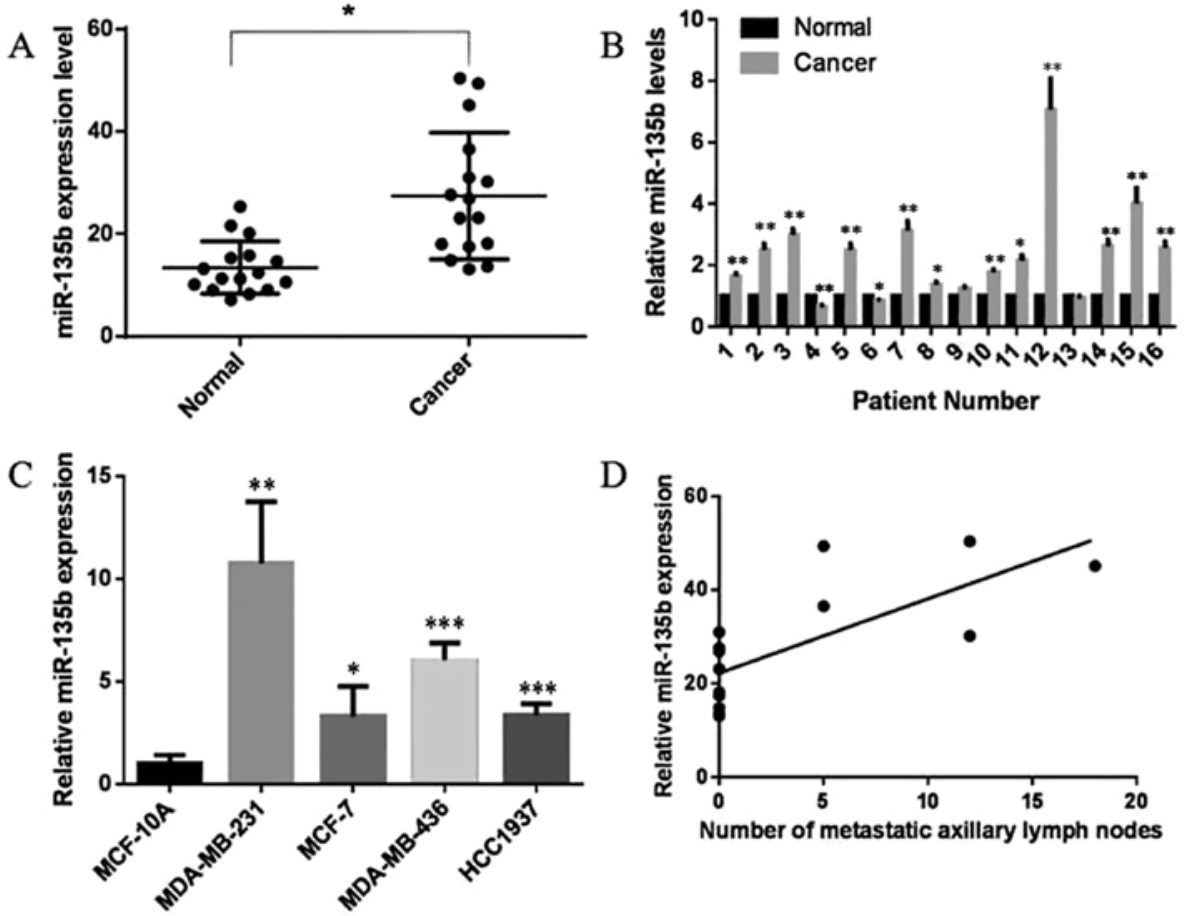

Figure 1. miR-135b is upregulated in human breast cancer cell lines and clinical specimens. The levels of miR-135b were measured by qRT-PCR and normalized to the expression of U6. (A) Relative miR-135b expression in 16 paired breast cancer tissues and matched adjacent normal breast tissues. " $\mathrm{P}<0.05$, Cancer vs. Normal. (B) Relative miR-135b expression in each patient according to the patient number. ${ }^{*} \mathrm{P}<0.05,{ }^{* *} \mathrm{P}<0.01$ vs. NC. (C) Relative expression of miR-135b in breast cancer cell lines MDA-MB-231, MCF-7, MDA-MB-436 and HCC-1937 compared to MCF-10A. Data represent the $2^{-\Delta \Delta C t}$ values \pm SD; ${ }^{*} \mathrm{P}<0.05,{ }^{* *} \mathrm{P}<0.01,{ }^{* * *} \mathrm{P}<0.001$ vs. MCF-10A. (D) A positive correlation between the number of metastatic axillary lymph nodes and the relative miR-135b expression; $\mathrm{r}=0.737,{ }^{* *} \mathrm{P}<0.01$.
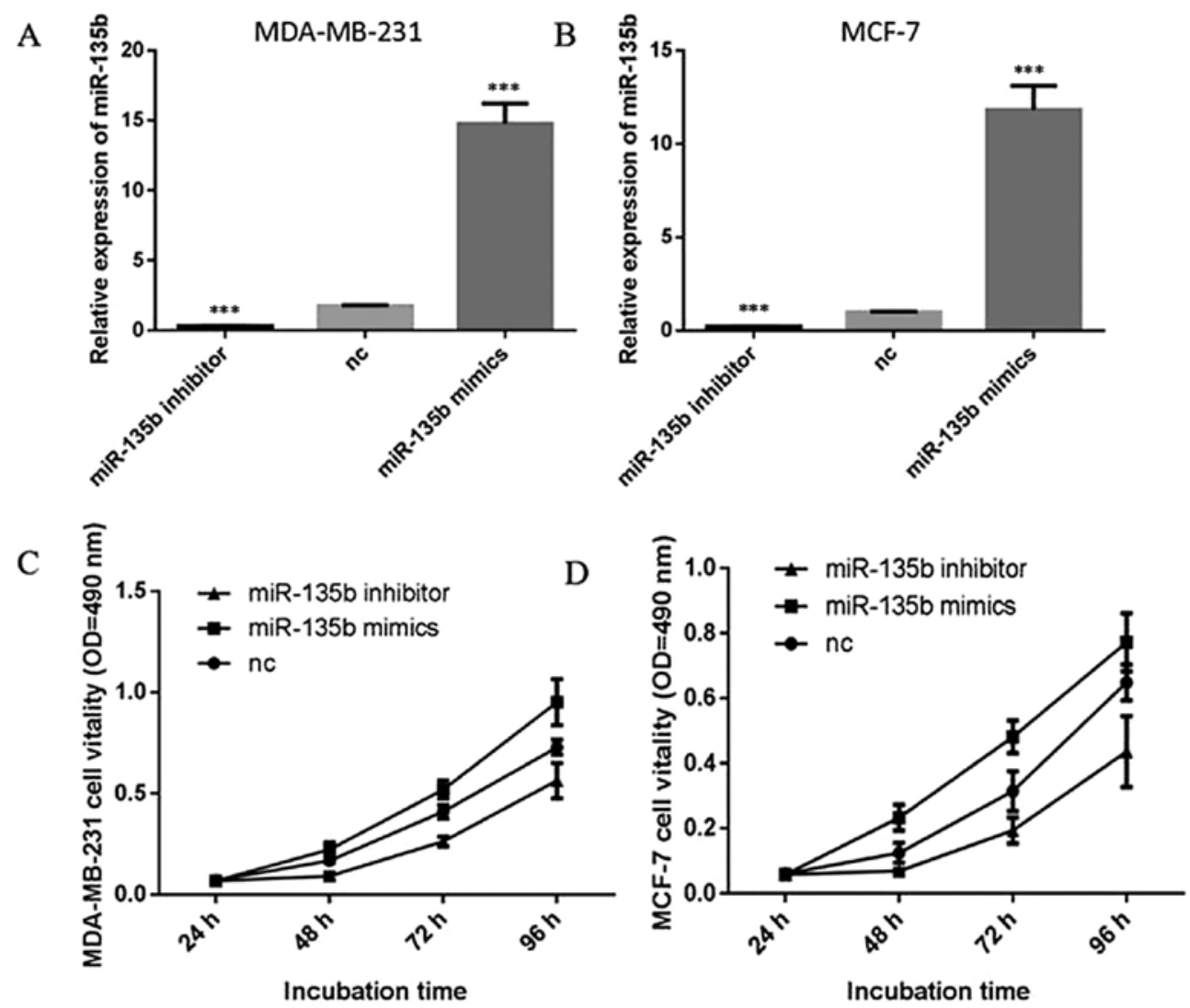

Figure 2. miR-135b promotes MDA-MB-231 and MCF-7 cell proliferation. (A and B) MDA-MB-231 and MCF-7 cells were transfected with miR-135b mimics or inhibitor or miR-NC at $100 \mathrm{nmol} / 1$ for $24 \mathrm{~h}$. Relative miR-135b expression was detected by qRT-PCR. Data represent the $2^{-\Delta \Delta \mathrm{Ct}}$ values $\pm \mathrm{SD} ;{ }^{* * *} \mathrm{P}<0.001$ vs. NC. (C and D) MDA-MB-231 and MCF-7 cells were transfected with miRNAs. MTT assay was performed to monitor the proliferation level of cells at 24, 48,72 and 96 h. Data represent $\mathrm{OD} 490 \mathrm{~nm} \pm \mathrm{SD} ;{ }^{*} \mathrm{P}<0.05$ vs. NC. 

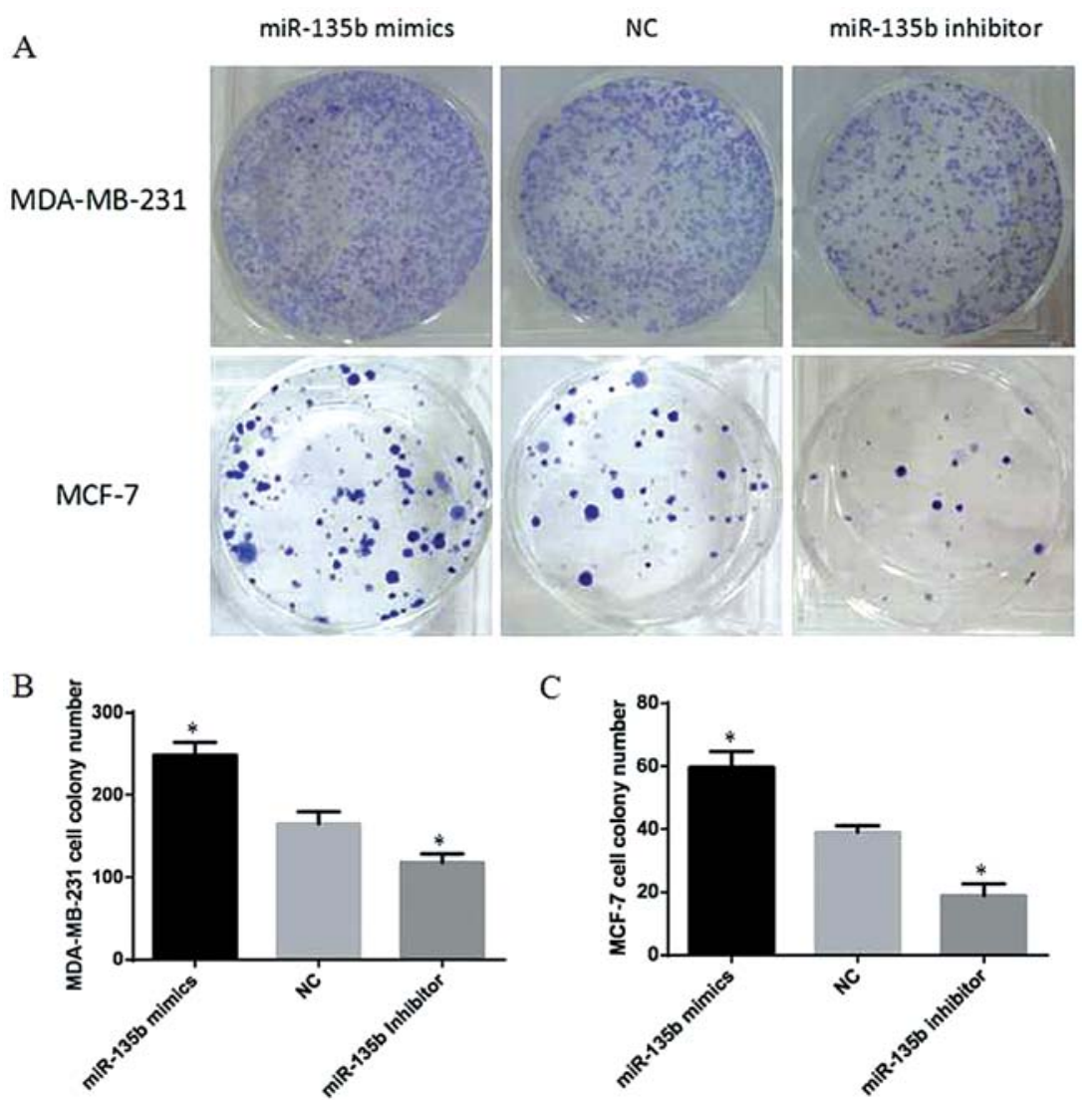

Figure 3. miR-135b promotes clony formation in MDA-MB-231 and MCF-7 cells. (A) Colony formation assay showed greater colony formation in the group transfected with miR-135b mimics compared with the NC group, and miR-135b inhibitor group showed the opposite result. (B and C) Colony formation efficiency in the two breast cancer cell lines. ${ }^{*} \mathrm{P}<0.05$ vs. NC.

proliferation of breast cancer cells. Two of the most representative breast cancer cell lines, MDA-MB-231 and MCF-7 cells were selected in our following experiments. These two cells were transiently transfected with miR-135b mimics, miR-135b inhibitor or negative control (NC) and the expression levels of miR-135b were detected by quantitative RT-PCR (qRT-PCR) $(\mathrm{P}<0.001$, Fig. 2A and B). Cell proliferation assay (MTT assay) indicated that overexpression of miR-135b in MDA-MB-231 and MCF-7 cells promoted an increment in cell proliferation $(\mathrm{P}<0.05$, Fig. $2 \mathrm{C}$ and $\mathrm{D})$. Inhibition of the endogenous miR135 b by miR-135b inhibitor led to a significant reduction in cell proliferation $(\mathrm{P}<0.05)$. Colony formation assays also showed much more colony formation in the group transfected with miR-135b mimics compared with the NC group, and miR-135b inhibitor group showed the opposite result $(\mathrm{P}<0.05$, Fig. 3). Our data indicated that miR-135b can promote cell proliferation in breast cancer cells in vitro.

miR-135b accelerates cell migration and invasion of breast cancer cells in vitro. To investigate how forced expression of miR-135b affects cellular migration and invasion, wound healing assays and Transwell assays were performed in MDA-MB-231 and MCF-7 cells. Cells were transfected with miR-135b mimics, miR-135b inhibitor or NC. As shown in Fig. 4, $24 \mathrm{~h}$ after drawing the 'scratch' line in the monolayer MDA-MB-231 cells, the miR-135b mimics group nearly filled the gap, the NC group still showed a clear gap in the scratched region, and miR-135b inhibitor group showed the opposite result $(\mathrm{P}<0.05, \mathrm{P}<0.001)$. The experiments carried out in MCF-7 cells also showed a similar trend $(\mathrm{P}<0.05, \mathrm{P}<0.001)$. The results indicate that overexpression of miR-135b in MDA-MB-231 and MCF-7 cells accelerated cellular migration. The Transwell invasion assay revealed that the number of MDA-MB-231 and MCF-7 cells penetrating the membrane significantly increased at $48 \mathrm{~h}$ after miR-135b mimic-transfection as compared to the NC group and miR-135b inhibitor group $(\mathrm{P}<0.05, \mathrm{P}<0.01$, Fig. 5). Together these results showed that overexpression of miR-135b can accelerate cellular migration and invasion in vitro.

$M i R-135 b$ regulates the cell cycle of breast cancer cells. Twenty-four hours after the transfection with miR-135b mimics, miR-135b inhibitor or NC in MCF-7 cells, flow cytometry analysis indicated that the percentage of G0/G1 phase cells $(58.02 \pm 0.41 \%)$ dramatically decreased in the miR$135 \mathrm{~b}$ mimics group, when compared with that of the NC group $(67.77 \pm 0.50 \%)$ and miR-135b inhibitor group $(72.33 \pm 0.58 \%)$ $(\mathrm{P}<0.05)$. At the same time, the proportion of S-phase cells increased in the miR-135b mimics group $(27.14 \pm 0.47 \%)$ compared with that of the NC group $(18.16 \pm 0.37 \%)$ and miR-135b inhibitor group $(16.52 \pm 0.36 \%)(\mathrm{P}<0.01, \mathrm{P}<0.001)$. The percentage of $\mathrm{G} 2 / \mathrm{M}$ phase cells was also elevated in the miR-135b mimics group $(14.84 \pm 0.22 \%)$ compared with that of the NC group $(14.07 \pm 0.25 \%)$ and miR-135b inhibitor group $(11.15 \pm 0.21 \%)(\mathrm{P}<0.01, \mathrm{P}<0.001)$. The experiments carried out in MDA-MB-231 cells also showed a similar trend 

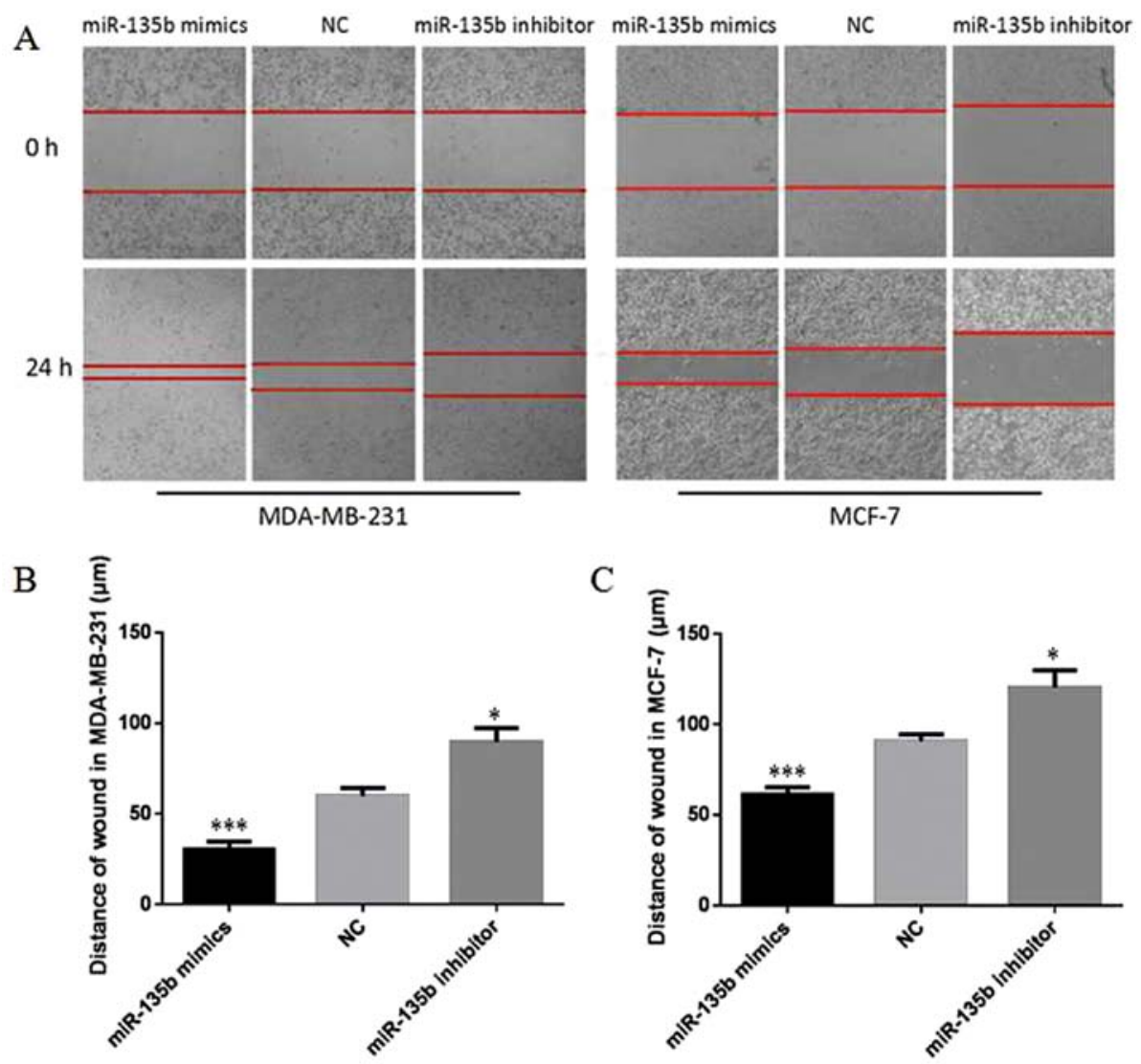

Figure 4. miR-135b promotes MDA-MB-231 and MCF-7 cell migration. (A) We transfected MDA-MB-231 and MCF-7 cells with $100 \mathrm{nmol} / 1 \mathrm{miR}-135 \mathrm{~b}$ mimics or inhibitor and detected changes in their motility using wound healing assay. (B and C) Distance of wound was correlated to cell migration ability. Results showed that cell migration was accelerated in miR-135b mimics group at $24 \mathrm{~h}$ after transfection, and miR-135b inhibitor group showed the opposite result. ${ }^{*} \mathrm{P}<0.05,{ }^{* * * *} \mathrm{P}<0.001$ vs. NC.

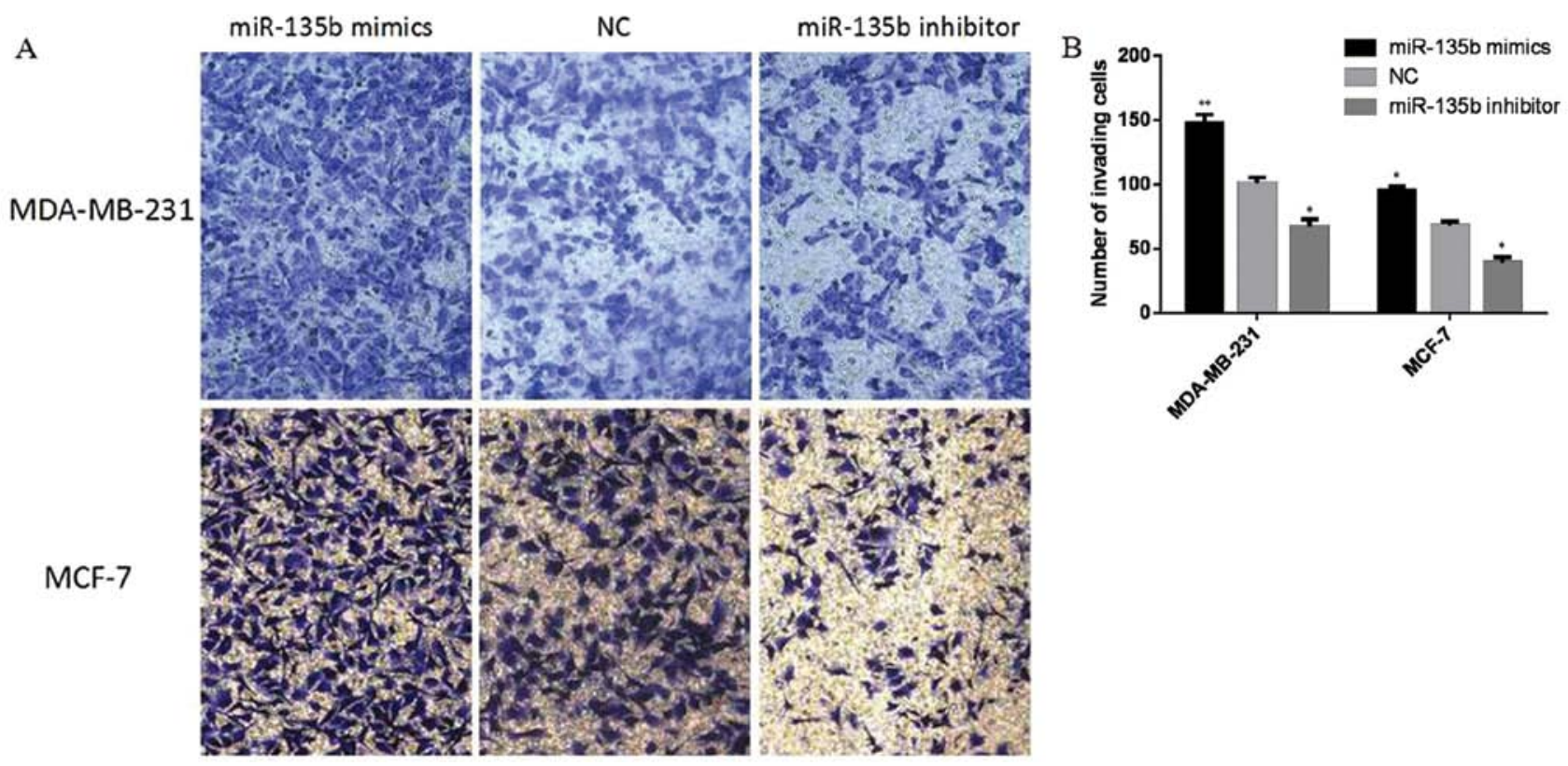

Figure 5. miR-135b promotes MDA-MB-231 and MCF-7 cell invasion. (A) We transfected MDA-MB-231 and MCF-7 cells with $100 \mathrm{nmol} / 1 \mathrm{miR}-135 \mathrm{~b}$ mimics or inhibitor and detected changes in their motility using Transwell assays. (B) Changes in the number of cells penetrating the membrane in Transwell invasion assay. The number of cells penetrating the membrane was more in miR-135b mimics group than that in NC group, and miR-135b inhibitor group showed the opposite trend. ${ }^{*} \mathrm{P}<0.05,{ }^{* *} \mathrm{P}<0.01$ vs. NC.

(Fig. 6A and B). These findings revealed that miR-135b can lead to the upregulation of S-phase and G2/M phase cells.
miR-135b regulates the expression of LATS2 and its downstream gene in the Hippo pathway. To explore the action 

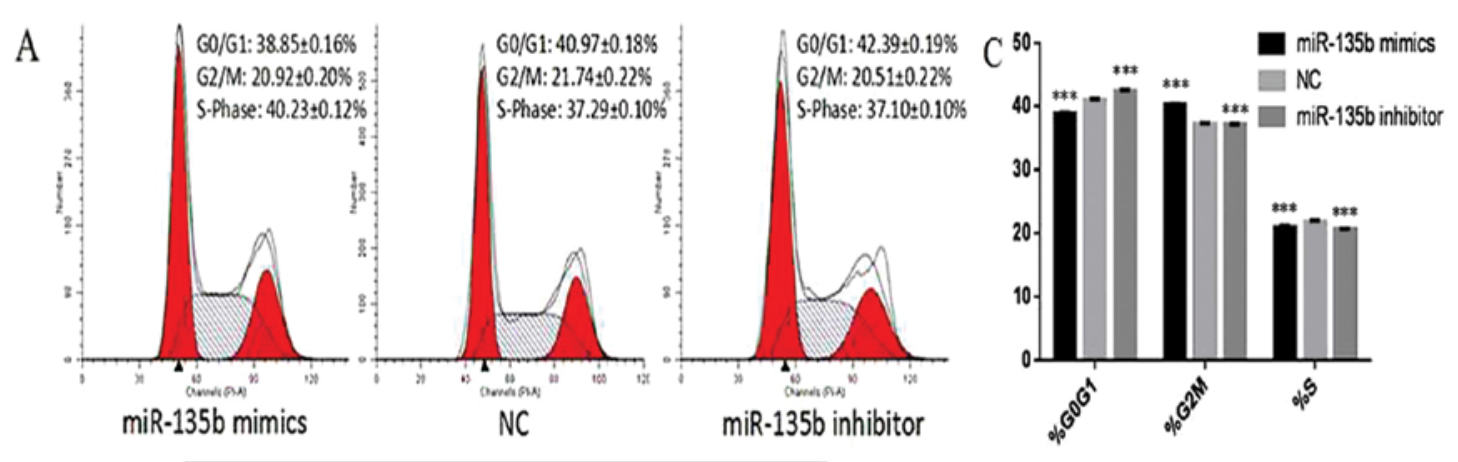

MDA-MB-231
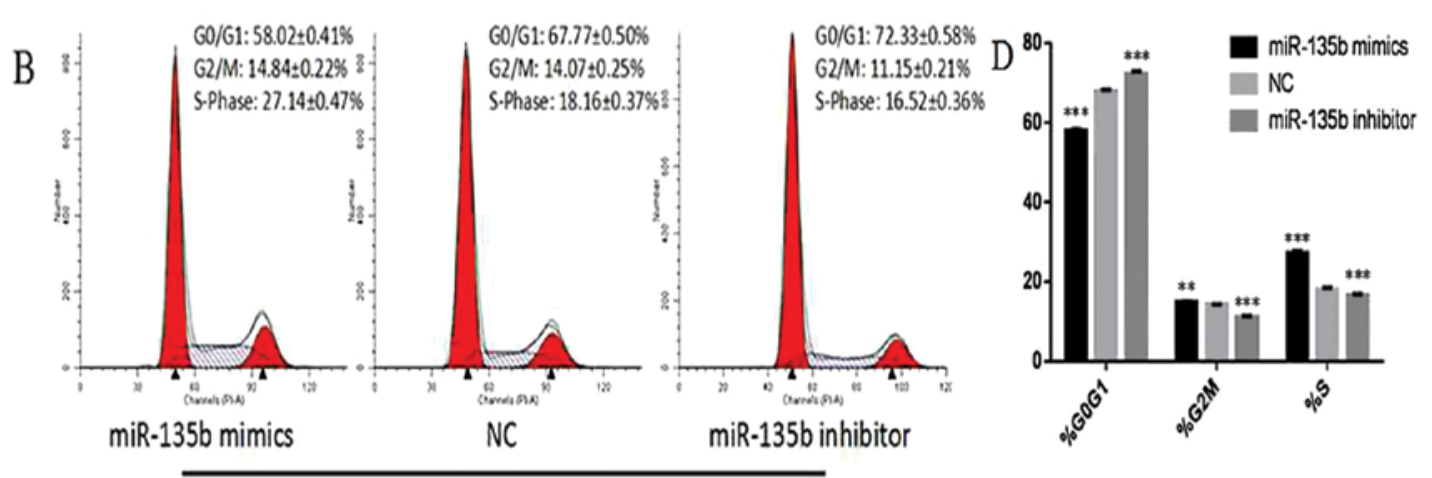

MCF-7

Figure 6. Effects of miR-135b on cell cycle in MDA-MB-231 and MCF-7 cells. (A and B) MDA-MB-231 and MCF-7 cells were transfected with miR-135b mimics or miR-135b inhibitor for $24 \mathrm{~h}$. Cell cycle distribution was analyzed by flow cytometry. (C and D) The respective proportion of G0/G1 phase, S-phase and $\mathrm{G} 2 / \mathrm{M}$ phase of each group. All data are presented as mean $\pm \mathrm{SD},{ }^{* *} \mathrm{P}<0.01,{ }^{* * *} \mathrm{P}<0.001 \mathrm{vs}$. NC.

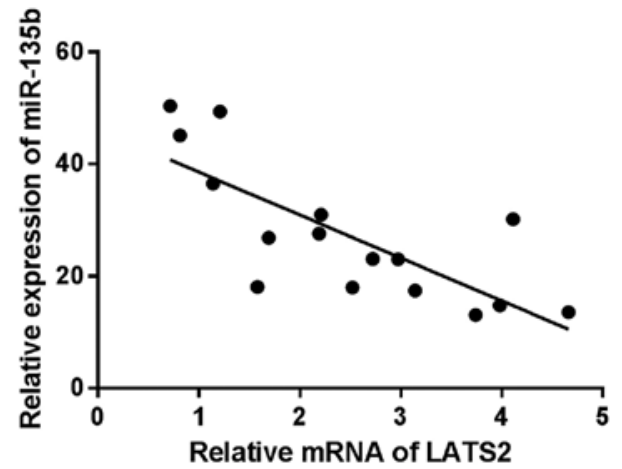

Figure 7. miR-135b levels were found to be markedly inversely correlated with LATS2 expression in clinical breast cancer specimens; $r=-0.765$, ${ }^{* * *} \mathrm{P}<0.01$.

mechanism of miR-135b in breast cancer, we screened the target genes of miR-135b using Targetscan and microRNA.org (http://www.targetscan.org/ and http://www.microrna.org). LATS2, an upstream regulator in the Hippo pathway, was identified as a candidate. Next, we investigate the correlation between the expression of miR-135b and LATS2 in clinical breast cancer specimens. Noteworthy, miR-135b levels were found to be markedly inversely correlated with LATS2 expression ( $r=-0.765, \mathrm{P}<0.01$, Fig. 7 ), indicating miR-135b might target LATS 2 mRNA in breast cancer. To confirm that miR$135 \mathrm{~b}$ can bind to the predicted site, we performed a luciferase reporter assay in the $293 \mathrm{~T}$ cell line. As shown in Fig. 8, the
A

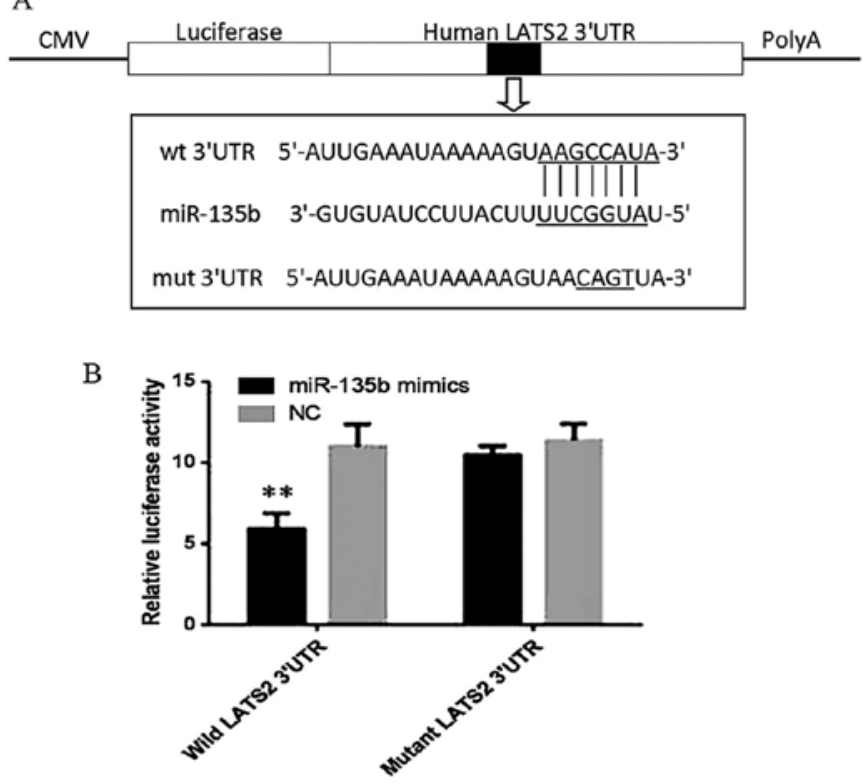

Figure 8. miR-135b regulates LATS2 expression by binding the 3 '-UTR of LATS2. (A) The binding site for miR-135b in the 3'-UTR of LATS2 mRNA. (B) The relative luciferase activity was measured in $293 \mathrm{~T}$ cells after co-transfection of the LATS2 3'-UTR or LATS2 3'-UTR mutant luciferase construct with either miR-135b mimics or miR-NC. Data represent means $\pm \mathrm{SD} ;{ }^{* * *} \mathrm{P}<0.01$ vs. NC.

luciferase activity significantly decreased after co-transfection with psi-CHECK-2/LATS2 3'-UTR and miR-135b mimics 


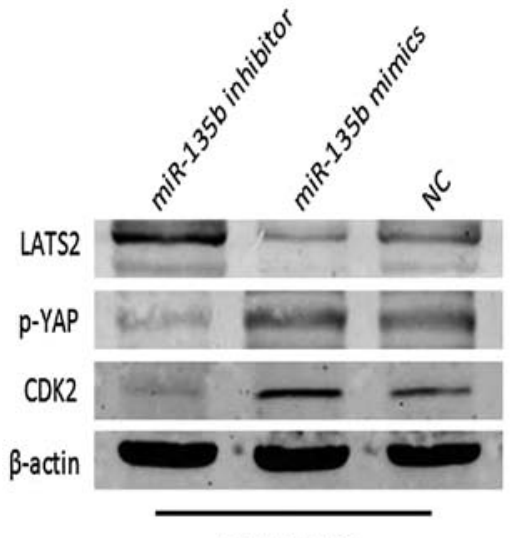

MDA-MB-231

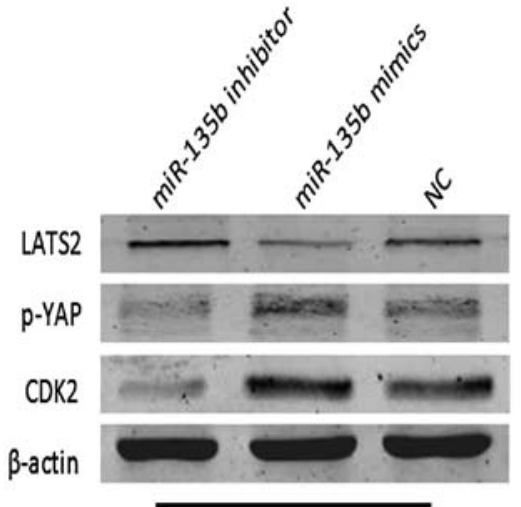

MCF-7

Figure 9. miR-135b downregulates LATS2 expression at protein level. CDK2 and p-YAP, can be inhibited by miR-135b and LATS2 axis at the protein level. $\beta$-actin was used as a control for loading the western blots; " $\mathrm{P}<0.05$ vs. NC.

A
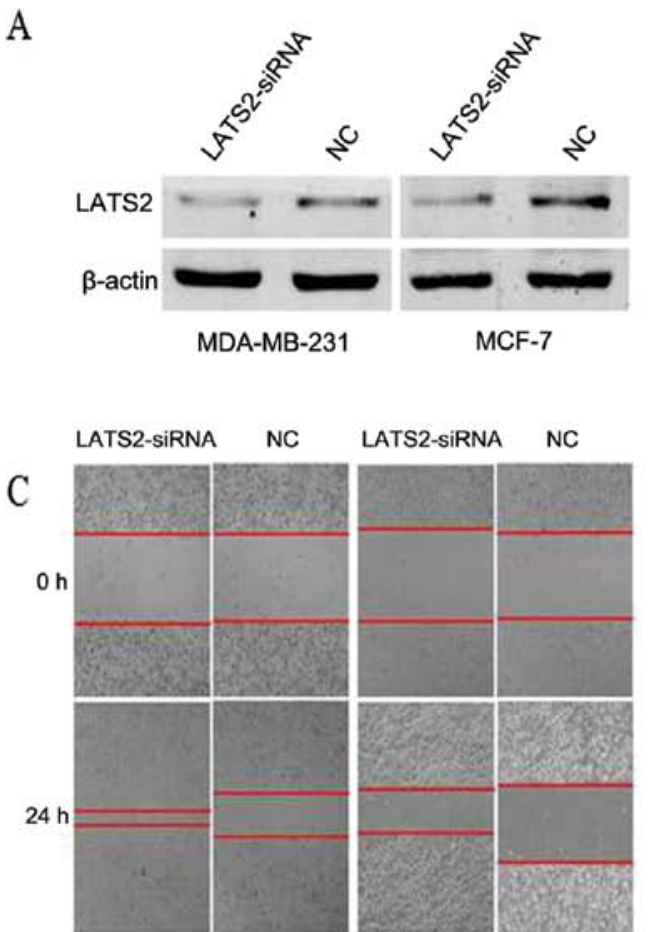

MDA-MB-231
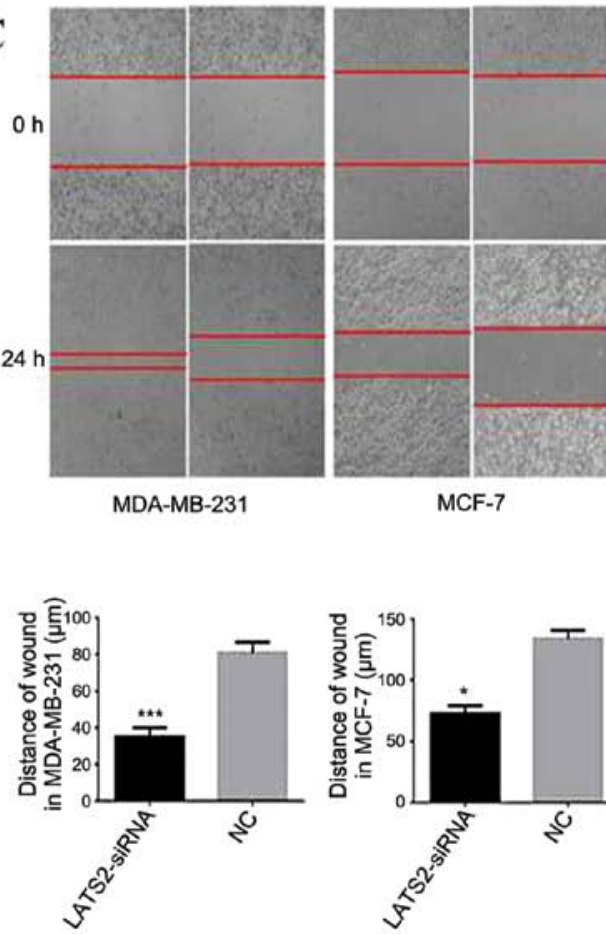

MCF-7

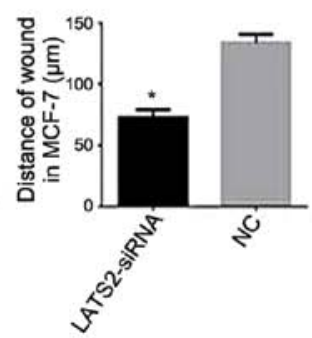

$\mathrm{B}$

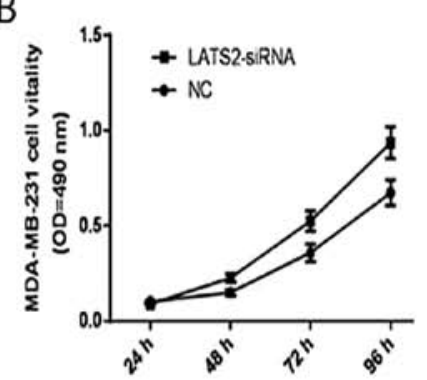

D

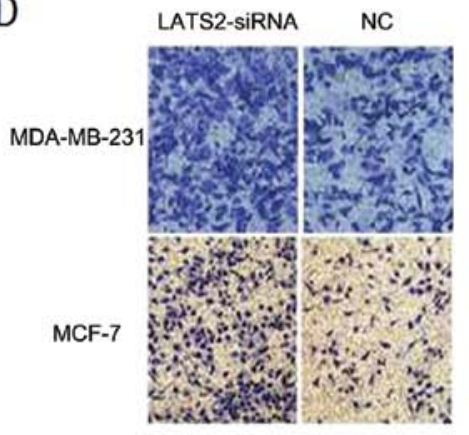

$\mathrm{E}$

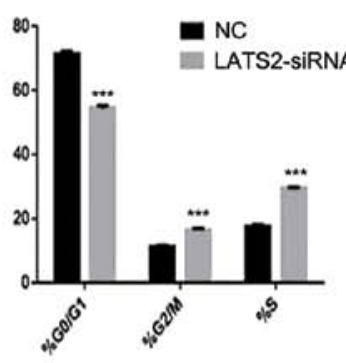

MDA-MB-231
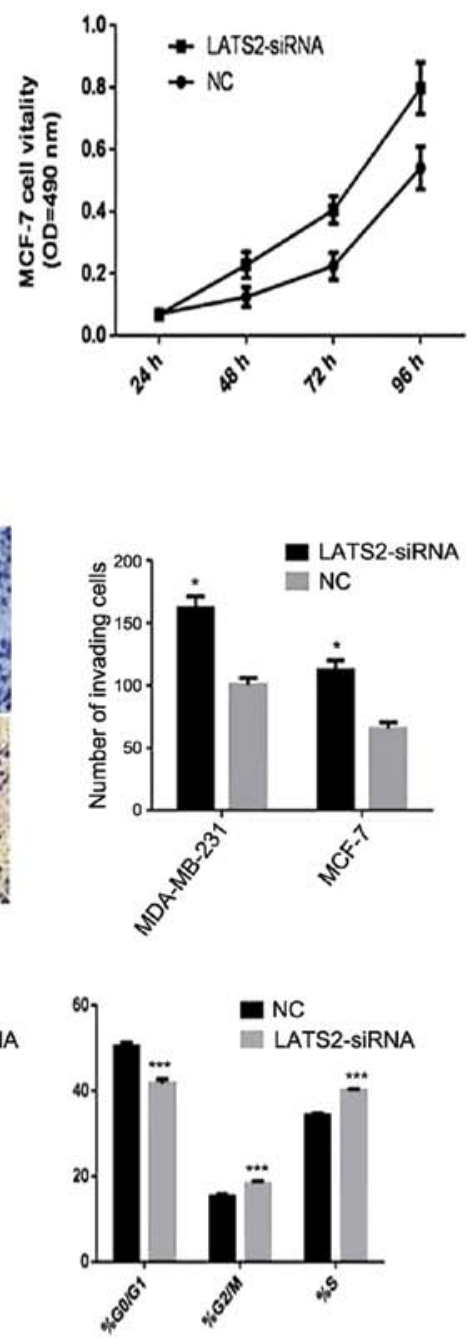

MCF-7

Figure 10. Effects of LATS2 in breast cancer cell proliferation, migration, invasion and cell cycle. (A) The level of LATS2 protein was decreased in LATS2 siRNA group compared with NC group in MDA-MB-231 and MCF-7 cells. ${ }^{*} \mathrm{P}<0.05$ vs. NC. (B) Cells transfected with LATS2 siRNA showed markedly stimulative cell proliferation compared with control siRNA. "P<0.05 vs. NC. (C and D) Inhibition of LATS2 promoted the migration and invasion ability. ${ }^{*} \mathrm{P}<0.05,{ }^{* * *} \mathrm{P}<0.001$ vs. NC. (E) Inhibition of LATS2 disrupted the cell cycle; ${ }^{* * *} \mathrm{P}<0.001$ vs. NC.

in comparison with control cells, suggesting that miR-135b specifically binds to the 3'-UTR of LATS2 mRNA. The impact of miR-135b transfection on LATS2 protein expression in MDA-MB-231 and MCF-7 cell line was respectively 
assessed using western blot assays (Fig. 9). We observed that miR-135b was capable of downregulating LATS2 in the cells at the protein level. The opposite result was obtained when the cells were treated with miR-135b inhibitor, indicating that miR-135b is able to attenuate the expression of LATS 2 in breast cancer cells. Further study demonstrated that the downstream gene of LATS2 in the Hippo pathway, such as CDK2 and p-YAP, can also be inhibited by miR-135b and LATS2 axis at the protein level (Fig. 9). Furthermore, silencing of LATS2 by LATS2-siRNA can promote proliferation, invasion, migration and disrupte the cell cycle in MDA-MB-231 and MCF-7 breast cancer cells (Fig. 10). Thus, our data indicated that miR-135b can promote cell growth and disrupt the cell cycle by regulating LATS2 and the Hippo pathway in breast cancer cells.

\section{Discussion}

The miRNAs have been confirmed as important regulators involved in different biological processes such as cell proliferation, metastasis, differentiation, transcriptional regulation and tumorigenesis (28). Dysregulation of miRNAs is connected with initiation and progression of breast cancer, since they may serve as oncogenes or tumor suppressors $(29,30)$. In the present study, we investigated the role of miR-135b in breast cancer and speculate the Hippo pathway as one of its possible mechanism.

The Hippo pathway was discovered 20 years ago in Drosophila melanogaster (31), it is regulated by various upstream signals, such as extracellular matrix (32), cell-cell contact (33), and cell stress (34). When the Hippo pathway is activated, phosphorylated mammalian sterile 20-like kinase $1 / 2$ (Mst1/2) forms a complex by interacting with Sav1 (also known as WW45) (35). The Mst1/2 complex directly phosphorylates the large tumor suppressor 1 and 2 (LATS1/2) (36) and MOBKL1A/B (also known as MOB1) that forms another kinase complex with LATS1/2 (37). Phosphorylated and activated LATS1/2 phosphorylates transcription coactivators YAP and TAZ at S127 and S89, respectively (38-40), leading to the YAP/TAZ cytoplasm retention by 14-3-3 or degradation (41). Unphosphorylated YAP and TAZ translocate into the nucleus to interact with transcription factors, such as TEAD1-4 (42), Smads (43), and p73 (44). As a regulatory factor in the Hippo pathway, LATS2 plays its tumor-suppressor role by downregulating YAP, a gene promoting breast cancer cell proliferation (45). It is reported that LATS2 can also inhibit cell growth at the G1/S transition by downregulating CDK2 kinase activity (11).

In our experiment, we first investigated the expression levels of miR-135b in 16-paired clinical breast cancer and adjacent normal specimens. Of note, we observed that the expression levels of miR-135b were remarkably increased in 13 of 16 samples relative to paired non-tumor tissues. Similar findings were reported in many different tumors, including hepatocellular carcinoma (19), colorectal cancer (21), osteosarcoma (26), as well as in glioblastoma multiforme cells (25). Based on this finding, we hypothesized that miR-135b might be a novel tumor-promoter miRNA in breast cancer. Then we investigated the specific role of miR-135b in two typical breast cancer cell lines, MDA-MB-231 and MCF-7. Cells were transfected with miR-135b mimics, miR-135b inhibitor or NC, respectively, to detect the gain-or-loss of function effects on various aspects of breast cancer biology. Our results showed that the exogenous overexpression of miR-135b regulated by miR-135b mimics significantly promoted proliferation and colony formation ability of breast cancer cells as measured by MTT and colony formation assays.

Moreover, cell migration and invasion ability was also significantly enhanced by overexpression of miR-135b. We found that miR-135b inhibitor distinctly arrests cancer cells at the G1 phase when compared with the cell cycle of NC group. Moreover, we explored the correlation between the expression levels of miR-135b and LATS2 in clinical breast cancer specimens. As expected, we observed a negative correlation between the two variables. We then further investigated the effects of miR-135b on LATS2 expression in breast cancer cells. Western blot assays demonstrated that miR-135b was able to downregulate LATS2 protein and its direct target genes (CDK2 and YAP) in the Hippo pathway. Luciferase reporter assay also identified that miR-135b could directly bind to the 3'UTR of LATS2. We concluded that knockdown of endogenous LATS2 can mimic the result of miR-135b upregulation in breast cancer. Thus, our results showed that miR-135b affected the Hippo pathway by downregulating the levels of LATS2 in breast cancer cells.

In resent years, several studies on miR-135b and cancer was accomplished. Lin et al identified that expression of miR-135b, LZTS1, LATS2 and nuclear TAZ predicts poor outcomes of non-small cell lung cancer (17). Li et al found that upregulation of miR-135b level was found to be inversely correlated with tumor capsule occurrence and serum hepatitis B virus E antigen level (19). In this experiment, we also tried to explore the relationship between clinical data and miR-135b levels. The number of metastatic axillary lymph nodes was found to have a positive correlation with the relative miR-135b expression in our cases, which suggested that miR-135b could be a reliable biological marker in diagnosis of breast cancer. Actually, we also analyzed the probable connections of miR-135b levels with age, tumor size, tumor stage, and molecular subtypes of breast cancer, but no significant correlation was observed. Since this is a pattern verified only in 16 clinical cases, the reliability is relatively low and needs to be confirmed in a larger number of samples.

Taken together, our findings demonstrated that miR-135b is upregulated in breast cancer tissues and cell lines, and is able to promote cellular proliferation, migration and invasion as well as disrupt the cell cycle in vitro via direct regulation of the expression of LATS2 and the Hippo pathway, indicating that miR-135b can serve as a potential therapeutic target for breast cancer.

\section{Acknowledgements}

This work was supported by grants from National Natural Science Foundation of China (no. 82172240). We sincerely thank all the teachers at the Central Laboratory of the Shanghai Tenth People's Hospital for their help and support.

\section{References}

1. World Health Organization: WHO fact sheet No. 297. World Health Organization, Geneva, 2006. 
2. Garzon R, Fabbri M, Cimmino A, Calin GA and Croce CM MicroRNA expression and function in cancer. Trends Mol Med 12: 580-587, 2006

3. Calin GA and Croce CM: MicroRNA signatures in human cancers. Nat Rev Cancer 6: 857-866, 2006.

4. Gregory RI, Chendrimada TP, Cooch N and Shiekhattar R: Human RISC couples microRNA biogenesis and posttranscriptional gene silencing. Cell 123: 631-640, 2005.

5. He L and Hannon GJ: MicroRNAs: Small RNAs with a big role in gene regulation. Nat Rev Genet 5: 522-531, 2004.

6. Esquela-Kerscher A and Slack FJ: Oncomirs - microRNAs with a role in cancer. Nat Rev Cancer 6: 259-269, 2006.

7. Ryan BM, Robles AI and Harris CC: Genetic variation in microRNA networks: The implications for cancer research. Nat Rev Cancer 10: 389-402, 2010.

8. Jay C, Nemunaitis J, Chen P, Fulgham P and Tong AW: miRNA profiling for diagnosis and prognosis of human cancer. DNA Cell Biol 26: 293-300, 2007.

9. Pan D: The hippo signaling pathway in development and cancer. Dev Cell 19: 491-505, 2010 .

10. Yabuta N, Okada N, Ito A, Hosomi T, Nishihara S, Sasayama Y, Fujimori A, Okuzaki D, Zhao H, Ikawa M, et al: Lats2 is an essential mitotic regulator required for the coordination of cell division. J Biol Chem 282: 19259-19271, 2007.

11. Li Y, Pei J, Xia H, Ke H, Wang H and Tao W: Lats2, a putative tumor suppressor, inhibits G1/S transition. Oncogene 22: 4398-4405, 2003.

12. Dong J, Feldmann G, Huang J, Wu S, Zhang N, Comerford SA, Gayyed MF, Anders RA, Maitra A and Pan D: Elucidation of a universal size-control mechanism in Drosophila and mammals. Cell 130: 1120-1133, 2007.

13. Oka T, Mazack V and Sudol M: Mst2 and Lats kinases regulate apoptotic function of Yes kinase-associated protein (YAP). J Biol Chem 283: 27534-27546, 2008

14. Xia Y and Gao Y: MicroRNA-181b promotes ovarian cancer cell growth and invasion by targeting LATS2. Biochem Biophys Res Commun 447: 446-451, 2014.

15. Fang L, Du WW, Yang W, Rutnam ZJ, Peng C,LiH, O'Malley YQ, Askeland RW, Sugg S, Liu M, et al: MiR-93 enhances angiogenesis and metastasis by targeting LATS2. Cell Cycle 11: 4352-4365, 2012

16. Cho WJ, Shin JM, Kim JS, Lee MR, Hong KS, Lee JH, Koo KH Park JW and Kim KS: miR-372 regulates cell cycle and apoptosis of ags human gastric cancer cell line through direct regulation of LATS2. Mol Cells 28: 521-527, 2009.

17. Lin CW, Chang YL, Chang YC, Lin JC, Chen CC, Pan SH, Wu CT, Chen HY, Yang SC, Hong TM, et al: MicroRNA-135b promotes lung cancer metastasis by regulating multiple targets in the Hippo pathway and LZTS1. Nat Commun 4: 1877, 2013.

18. He Y, Wang J, Wang J, Yung VY, Hsu E, Li A, Kang Q, Ma J, Han Q, Jin P, et al: MicroRNA-135b regulates apoptosis and chemoresistance in colorectal cancer by targeting large tumor suppressor kinase 2. Am J Cancer Res 5: 1382-1395, 2015.

19. Li Y, Xu D, Bao C, Zhang Y, Chen D, Zhao F, Ding J, Liang L, Wang Q, Liu L, et al: MicroRNA-135b, a HSF1 target, promotes tumor invasion and metastasis by regulating RECK and EVI5 in hepatocellular carcinoma. Oncotarget 6: 2421-2433, 2015.

20. Zhang L, Sun ZJ, Bian Y and Kulkarni AB: MicroRNA-135b acts as a tumor promoter by targeting the hypoxia-inducible factor pathway in genetically defined mouse model of head and neck squamous cell carcinoma. Cancer Lett 331: 230-238, 2013.

21. Nagel R, le Sage C, Diosdado B, van der Waal M, Oude Vrielink JA, Bolijn A, Meijer GA and Agami R: Regulation of the adenomatous polyposis coli gene by the miR-135 family in colorectal cancer. Cancer Res 68: 5795-5802, 2008.

22. Valeri N, Braconi C, Gasparini P, Murgia C, Lampis A, Paulus-Hock V, Hart JR, Ueno L, Grivennikov SI, Lovat F, et al: MicroRNA-135b promotes cancer progression by acting as a downstream effector of oncogenic pathways in colon cancer. Cancer Cell 25: 469-483, 2014.

23. Wu W, Wang Z, Yang P, Yang J, Liang J, Chen Y, Wang H, Wei G, Ye S and Zhou Y: MicroRNA-135b regulates metastasis suppressor 1 expression and promotes migration and invasion in colorectal cancer. Mol Cell Biochem 388: 249-259, 2014.

24. He YQ, Sheng JQ, Ling XL, Fu L, Jin P, Yen L and Rao J: Estradiol regulates miR-135b and mismatch repair gene expressions via estrogen receptor- $\beta$ in colorectal cells. Exp Mol Med 44: 723-732, 2012
25. Xiao S, Yang Z, Lv R, Zhao J, Wu M, Liao Y and Liu Q: miR-135b contributes to the radioresistance by targeting GSK3 $\beta$ in human glioblastoma multiforme cells. PLoS One 9: e108810, 2014.

26. Pei H, Jin Z, Chen S, Sun X, Yu J and Guo W: MiR-135b promotes proliferation and invasion of osteosarcoma cells via targeting FOXO1. Mol Cell Biochem 400: 245-252, 2015.

27. Wu CW, Ng SC, Dong Y, Tian L, Ng SS, Leung WW, Law WT, Yau TO, Chan FK, Sung JJ, et al: Identification of microRNA$135 \mathrm{~b}$ in stool as a potential noninvasive biomarker for colorectal cancer and adenoma. Clin Cancer Res 20: 2994-3002, 2014.

28. Wu WK, Lee CW, Cho CH, Fan D, Wu K, Yu J and Sung JJ: MicroRNA dysregulation in gastric cancer: A new player enters the game. Oncogene 29: 5761-5771, 2010.

29. Luo Q, Li X, Li J, Kong X, Zhang J, Chen L, Huang Y and Fang L: MiR-15a is underexpressed and inhibits the cell cycle by targeting CCNE1 in breast cancer. Int J Oncol 43: 1212-1218, 2013.

30. Li J, Kong X, Zhang J, Luo Q, Li X and Fang L: Correction: MiRNA-26b inhibits proliferation by targeting PTGS2 in breast cancer. Cancer Cell Int 13: 17, 2013.

31. Justice RW, Zilian O, Woods DF, Noll M and Bryant PJ: The Drosophila tumor suppressor gene warts encodes a homolog of human myotonic dystrophy kinase and is required for the control of cell shape and proliferation. Genes Dev 9: 534-546, 1995.

32. Dupont S, Morsut L, Aragona M,Enzo E, Giulitti S, Cordenonsi M, Zanconato F, Le Digabel J, Forcato M, Bicciato S, et al: Role of YAP/TAZ in mechanotransduction. Nature 474: 179-183, 2011.

33. Zhao B, Wei X, Li W, Udan RS, Yang Q, Kim J, Xie J, Ikenoue T, $\mathrm{Yu} \mathrm{J}, \mathrm{Li} \mathrm{L}$, et al: Inactivation of YAP oncoprotein by the Hippo pathway is involved in cell contact inhibition and tissue growth control. Genes Dev 21: 2747-2761, 2007.

34. Mohseni M, Sun J, Lau A, Curtis S, Goldsmith J, Fox VL, Wei C, Frazier M, Samson O, Wong KK, et al: A genetic screen identifies an LKB1-MARK signalling axis controlling the Hippo-YAP pathway. Nat Cell Biol 16: 108-117, 2014.

35. Callus BA, Verhagen AM and Vaux DL: Association of mammalian sterile twenty kinases, Mst1 and Mst2, with hSalvador via C-terminal coiled-coil domains, leads to its stabilization and phosphorylation. FEBS J 273: 4264-4276, 2006.

36. Chan EH, Nousiainen M, Chalamalasetty RB, Schäfer A, Nigg EA and Silljé HH: The Ste20-like kinase Mst2 activates the human large tumor suppressor kinase Lats1. Oncogene 24: 2076-2086, 2005.

37. Praskova M, Xia F and Avruch J: MOBKL1A/MOBKL1B phosphorylation by MST1 and MST2 inhibits cell proliferation. Curr Biol 18: 311-321, 2008

38. Hao Y, Chun A, Cheung K, Rashidi B and Yang X: Tumor suppressor LATS1 is a negative regulator of oncogene YAP. J Biol Chem 283: 5496-5509, 2008.

39. Oka T, Mazack V and Sudol M: Mst2 and Lats kinases regulate apoptotic function of Yes kinase-associated protein (YAP). J Biol Chem 283: 27534-27546, 2008.

40. Lei QY, Zhang H, Zhao B, Zha ZY, Bai F, Pei XH, Zhao S, Xiong Y and Guan KL: TAZ promotes cell proliferation and epithelial-mesenchymal transition and is inhibited by the hippo pathway. Mol Cell Biol 28: 2426-2436, 2008.

41. Kanai F, Marignani PA, Sarbassova D, Yagi R, Hall RA, Donowitz M, Hisaminato A, Fujiwara T, Ito Y, Cantley LC, et al: TAZ: A novel transcriptional co-activator regulated by interactions with 14-3-3 and PDZ domain proteins. EMBO J 19: 6778-6791, 2000

42. Zhang H, Liu CY, Zha ZY, Zhao B, Yao J, Zhao S, Xiong Y, Lei QY and Guan KL: TEAD transcription factors mediate the function of TAZ in cell growth and epithelial-mesenchymal transition. J Biol Chem 284: 13355-13362, 2009.

43. Varelas X, Sakuma R, Samavarchi-Tehrani P, Peerani R, Rao BM, Dembowy J, Yaffe MB, Zandstra PW and Wrana JL: TAZ controls Smad nucleocytoplasmic shuttling and regulates human embryonic stem-cell self-renewal. Nat Cell Biol 10: $837-848,2008$

44. Strano S, Munarriz E, Rossi M, Castagnoli L, Shaul Y, Sacchi A, Oren M, Sudol M, Cesareni G and Blandino G: Physical interaction with Yes-associated protein enhances p73 transcriptional activity. J Biol Chem 276: 15164-15173, 2001.

45. Wang X, Su L and Ou Q: Yes-associated protein promotes tumour development in luminal epithelial derived breast cancer. Eur J Cancer 48: 1227-1234, 2012. 